\title{
Lavado vesical de bovinos com hematúria enzoótica: padronização de técnica de colheita, obtenção de amostras e avaliação citopatológica
}

\author{
Bovine urinary bladder washing with enzootic hematuria: standardization of \\ harvesting technique, sample collection and cytopathological evaluation
}

\author{
Marcel Arcanjo Silva Azevedo ${ }^{*}$, Eduardo Vargas de Oliveira², Leonardo Oliveira Trivilin², \\ Louisiane de Carvalho Nunes ${ }^{2}$
}

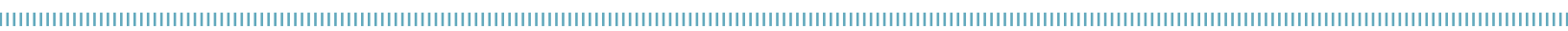

RESUMO: A hematúria enzoótica bovina é uma doença crônica que causa neoplasias na bexiga, e o exame citopatológico poderia auxiliar no diagnóstico precoce. Objetivou-se padronizar a técnica de colheita, obtenção de amostras e avaliação citopatológica do lavado vesical de bovinos com hematúria enzoótica bovina. Foram utilizadas 10 vacas, adultas, distribuídas em dois grupos. No grupo A foi recuperado todo o líquido vesical infundido, no grupo B foi recuperado apenas o último lavado. Os lavados foram submetidos à avaliação citopatológica. Apesar do volume final de líquido vesical ter sido maior no grupo $\mathrm{A}$, em relação ao número de células, não houve diferença significativa $(p>0,05)$ entre os grupos. A quantidade de células inflamatórias e células epiteliais obtidas por amostra revelou que nos dois grupos todos os animais apresentavam mais células inflamatórias do que epiteliais, entretanto, não houve diferença entre o tipo de colheita realizada. As células epiteliais foram encontradas em $60 \%$ dos casos e as alteraçôes morfológicas observadas foram discretas, não sendo possível classificar nenhuma amostra como hiperplásica ou neoplásica. Os dados deste estudo permitiram concluir que o exame citopatológico do lavado vesical de bovinos pode auxiliar no diagnóstico da hematúria enzoótica bovina e que os dois métodos de colheita empregados mostraram-se adequados para obtenção de amostras viáveis. A avaliação citopatológica permitiu a identificaçáo de lesóes não neoplásicas predominantemente inflamatórias. Acredita-se que a utilização de técnicas moleculares com biomarcadores em amostras citológicas seria importante para detectar precocemente lesóes pré-neoplásicas ou neoplásicas nesses animais.

PALAVRAS-CHAVE: citopatologia; coleta; líquido vesical.

\begin{abstract}
The bovine enzootic hematuria is a chronic disease that causes tumors in the bladder, and the cytophatologic test could assist in the early diagnosis. Aimed to standardize the technique of harvesting, obtaining samples and cytophatologic evaluation of bovine urinary bladder washing with bovine enzootic hematuria, 10 adult cows were divided into two groups: A (all the liquid infused in the bladder was recovered) and B (only the latter liquid was recovered). Liquids recovered were subjected to cytophatological evaluation. It was observed that the final volume of bladder liquid was higher in group $\mathrm{A}$, however, in relation to the number of cells, no significant difference $(p>0.05)$ was observed between groups. The amount of inflammatory cells and epithelial cells obtained per sample revealed that in both groups all animals had more inflammatory cells than epithelial cells, however, there was no difference between the type of washing done. The epithelial cells were found in $60 \%$ of cases, the alterations observed were discretes and it was not possible to classify any sample as hyperplastic or neoplastic. Data from this study showed that the cytophatological examination of bovine urinary bladder washing may aid in the diagnosis of bovine enzootic hematuria and the two harvesting methods employed were adequate for obtaining viable samples. Cytopathological evaluation allowed the identification of non-neoplastic lesions predominantly inflammatory. It is believed that the use of molecular markers in cytological samples is important for early detection of pre-neoplastic or neoplastic lesions in these animals.
\end{abstract}

KEYWORDS: cytopathology; collection; liquid bladder.

\footnotetext{
'Programa de pós-graduação em Ciências Veterinárias, Universidade Federal do Espírito Santo (UFES) - Alegre (ES), Brasil.

${ }^{2}$ Departamento de Medicina Veterinária, UFES - Alegre (ES), Brasil.

*Autor correspondente: marcel.arcanjo@hotmail.com

Recebido em: 25/10/2013. Aceito em: 28/10/2015
} 


\section{INTRODUÇÃO}

O exame citopatológico da urina é usualmente empregado no diagnóstico de pacientes com suspeita de câncer de bexiga e no seguimento destes após terapêutica. Suas vantagens compreendem a facilidade de coleta e o fato de não ser invasivo. As desvantagens são a subjetividade de critérios, a influência da experiência do citopatologista e também a baixa sensibilidade do método, ao redor de $35 \%$, especialmente para tumores de baixo grau. Por outro lado, a especificidade da técnica é extremamente elevada, estando em torno de $94 \%$, o que significa que a existência de câncer urotelial pode ser alta, mesmo com exame cistoscópico normal (Sociedade Brasileira de Urologia e Sociedade Brasileira de Patologia, 2008).

Estudos retrospectivos mostraram que na medicina veterinária o exame citológico é um método de suma importância para confirmar, sugerir ou afastar o diagnóstico de diversas afecçóes, em todas as espécies animais. No entanto, esses dados revelaram que a utilizaçăo do exame em bovinos é menos frequente quando comparada aos cáes e gatos (Ventura et al., 2012).

Atualmente, o exame citopatológico tem sido empregado na bovinocultura principalmente na avaliaçáo dos lavados traqueobrônquico e broncoalveolar de bezerros (Benesi et al., 2012), na dinâmica da celularidade do colostro de vacas (Gomes et al., 2011) e ainda no diagnóstico de endometrites (CARneIro, 2011).

Na região sul do Espírito Santo a hematúria enzoótica bovina (HEB) é uma doença de elevada prevalência (Silva et al., 2009) e tem sido responsável por grandes perdas econômicas devido à morte de animais ou à redução da produção leiteira, sendo o diagnóstico precoce difícil de ser estabelecido por ser uma doença crônica (Nunes, 2009).

Apesar da ampla utilização do exame citopatológico para o diagnóstico de neoplasias de bexiga em humanos por meio do lavado vesical (Sociedade Brasileira de Urologia e Sociedade Brasileira de Patologia, 2008), seu emprego na medicina veterinária limita-se à rotina da clínica médica de cáes e gatos (Raskin; Meyer, 2011).

Diante do exposto, nota-se que em animais de grande porte, especialmente bovinos, técnicas de exame direto como a citologia de bexiga não são utilizadas. Dessa forma, a padronização da técnica de colheita do lavado vesical nessa espécie seria importante, visto que poderia auxiliar no diagnóstico clínico e precoce de diversas enfermidades, inclusive da HEB. Objetivou-se com esta pesquisa padronizar a técnica de colheita, obtençáo de amostras e avaliação citopatológica do lavado vesical de bovinos com HEB.

\section{MATERIAL E MÉTODOS}

\section{Seleção dos animais e coleta das amostras}

Foram utilizadas 10 vacas adultas, provenientes de propriedades localizadas em municípios da microrregião do Caparaó, Espírito Santo, endêmicos para Pteridium aquilinum e com histórico comprovado de HEB. A composiçáo da amostragem foi feita por conveniência, após o preenchimento do Termo de Consentimento Livre e Esclarecido assinado pelo proprietário do animal. Esta pesquisa foi aprovada pela Comissão de Ética no uso de animais sob protocolo $n^{\circ}$ 094/2011.

Todos os animais avaliados apresentavam sangue na urina no momento da coleta ou cursaram com o quadro clínico de hematúria no período de até dois anos.

Inicialmente, os animais passaram por um exame físico de inspeção geral. Em seguida foi realizada a contenção física em bretes apropriados.

Em cada animal procedeu-se a lavagem da regiáo perineal com água e sabão neutro, seguida da secagem com papel toalha. Com auxílio de espéculo vaginal descartável localizou-se o meato urinário externo e introduziu-se a sonda de Folley $\mathrm{n}^{\circ} 24 \mathrm{RUSCH}$ (S0060, MARCA RUSCH) umedecida com lidocaína spray. Após essa fase, uma seringa estéril descartável contendo $60 \mathrm{~mL}$ de ar foi usada para inflar o balão da sonda impedindo assim sua saída. Um volume total de $300 \mathrm{~mL}$ de solução fisiológica $(\mathrm{NaCl}$ 0,9\%) foi infundido pela extremidade da sonda no interior da bexiga. Em seguida, um processo de aspiração e infusão da solução foi repetido por dez vezes consecutivas utilizando-se uma seringa de $60 \mathrm{~mL}$, para promover o turbilhonamento do líquido no interior da vesícula urinária (Fig. 1).

Após esse procedimento foram testadas duas formas de recuperação do lavado vesical, com dois grupos experimentais de cinco animais cada. No grupo A foi recuperado todo o líquido vesical infundido e armazenado em Erlenmeyers estéreis com capacidade de dois litros, devidamente identificados e vedados (Fig. 2). No grupo B foi recuperado apenas o último aspirado e armazenado em tubos plásticos tipo Falcon com capacidade de $15 \mathrm{~mL}$ (Fig. 3). Quando necessário, utilizou-se mais de um tubo por animal. Todo material coletado foi acondicionado em caixas isotérmicas contendo gelo para o transporte até o Laboratório de Patologia Animal do Hospital Veterinário da Universidade Federal do Espírito Santo.

\section{Processamento das amostras e exame citopatológico}

Inicialmente, todo material coletado foi redistribuído em tubos tipo Falcon de $60 \mathrm{~mL}$ e submetido à centrifugação a $1.500 \mathrm{rpm}$ durante 6 minutos em centrífuga refrigerada (NT 825, MARCA 
NovaTÉCNICA) a $25^{\circ}$ C. Após a centrifugação, o sobrenadante foi desprezado e o precipitado utilizado para uma nova centrifugaçáo repetindo-se o processo por várias vezes até que o volume final fosse igual a $10 \mathrm{~mL}$. A amostra foi homogeneizada com auxílio de pipeta de Pasteur e centrifugada em citocentrífuga (CT14, MARCA TEKLAB CITOLÓGICA). Em cada citobloco foi utilizado um volume de $350 \mathrm{~mL}$ do líquido para confecção da lâmina. De cada amostra foram preparadas duas
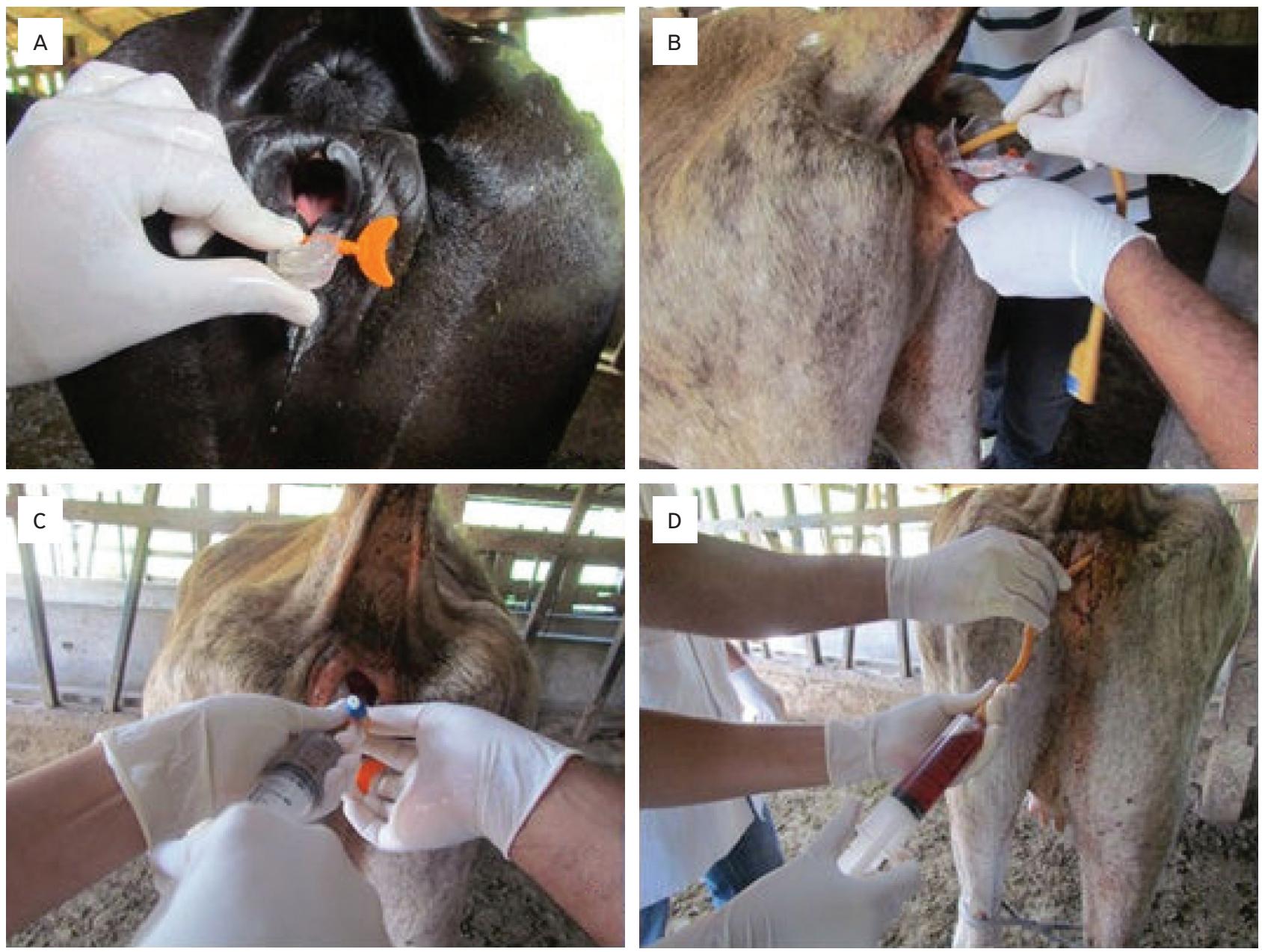

Figura 1. Coleta de lavado vesical em bovinos com hematúria enzoótica. (A) Localização do meato urinário externo; (B) introdução da sonda pelo meato urinário externo; (C) infusão da solução fisiológica ( $\mathrm{NaCl}$ 0,9\%); (D) processo de turbilhonamento do lavado.
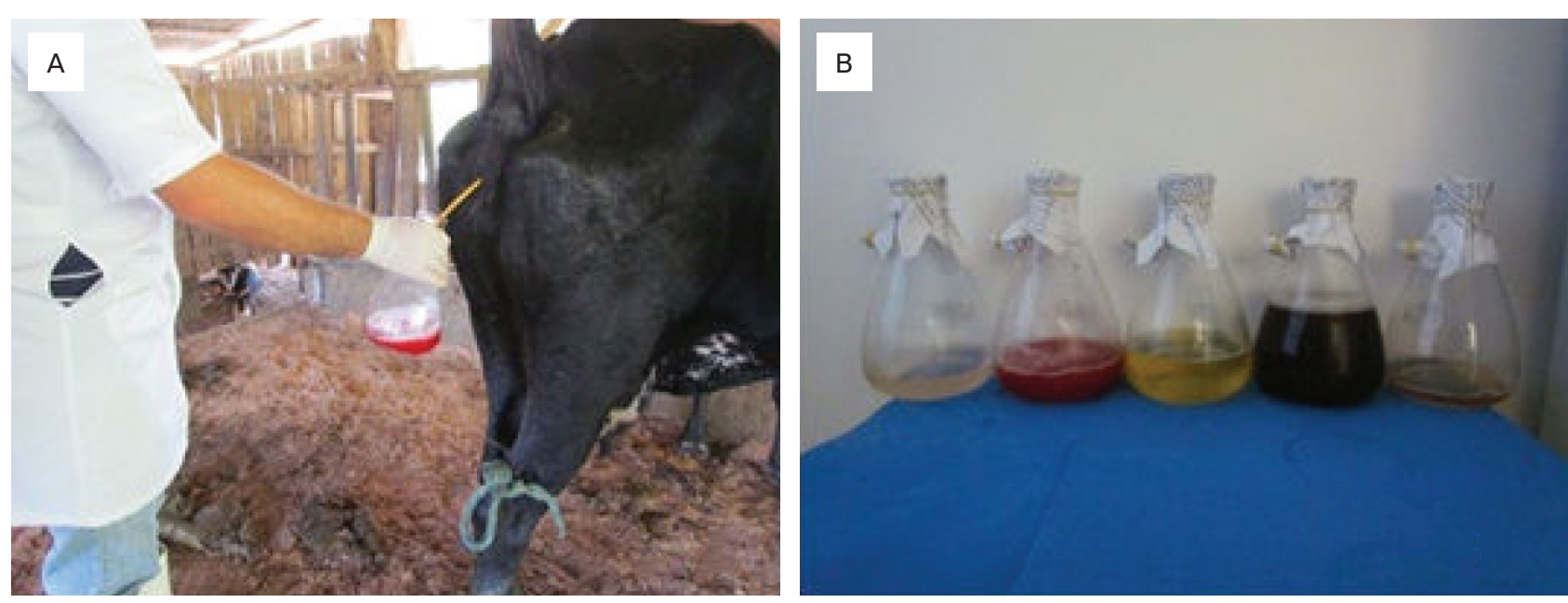

Figura 2. Recuperação do lavado vesical do grupo A. (A) Utilização do recipiente Erlenmeyer estéril com capacidade de dois litros para armazenagem de todo o lavado vesical obtido; (B) amostras devidamente identificadas após a coleta. 
lâminas, que foram fixadas em solução de metanol por 3 a 5 minutos, e coradas pelo método de Giemsa durante 30 minutos. Em seguida, as lâminas foram montadas em resina sintética.

A avaliação citopatológica foi realizada em microscópio óptico comum. A quantificação celular utilizou objetiva de 40x em 5 campos distintos, sendo que em cada campo foram contadas todas as células epiteliais e inflamatórias e obtido o valor médio. Também foram avaliadas as alteraçôes morfológicas nas células da mucosa vesical conforme Raskin; MeYer (2011).

\section{Análise estatística}

Os dados obtidos foram analisados por estatística descritiva. A avaliação da média do número total de células obtidas foi feita por análise de variância (ANOVA) seguida do teste de Tukey a 5\%. Para avaliação entre o tipo de coleta e a quantidade de células obtidas utilizou-se o teste não paramétrico de Kolmogorov-Smirnov a 5\%.

\section{RESULTADOS E DISCUSSÃO}

Dos animais avaliados, sete apresentavam macro-hematúria e três micro-hematúria. Em relação ao histórico clínico, 8 haviam cursado com quadro de HEB no período de até 2 anos antes da coleta e 2 apresentavam hematúria há menos de 30 dias. É importante destacar que todos os animais que apresentaram micro-hematúria tinham histórico de HEB há mais de um ano. Isso comprova que a hematúria pode ocorrer de forma descontínua ou intermitente.

O quadro de macro-hematúria é caracterizado pela coloração avermelhada da urina que, após a centrifugação, forma um sedimento de eritrócitos, enquanto que a micro-hematúria revela eritrócitos na urina apenas na avaliação microscópica (Rosenberger, 1971). No presente experimento, a macro-hematúria foi o sinal clínico principal observado na maioria dos animais. Esse achado é considerado o sinal cardinal da HEB (PAmukcu et al., 1976), que se inicia com micro-hematúria (Rosenberger, 1971).

MaXie; Newmann (2007) citaram que a micro-hematúria vista na $\mathrm{HEB}$ pode estar associada a petéquias, equimoses e sufusóes no urotélio dos cálices renais, pelve renal, ureter e bexiga, ou ocorrer antes mesmo de surgirem lesóes macroscopicamente visíveis. Neste experimento, a micro-hematúria foi verificada apenas nos animais que possuíam histórico clínico de hematúria em períodos de até dois anos que, segundo ToKARnia et al. (2000), apesar de casos de cura definitiva não serem conhecidos, períodos de remissão, sem sangramento, que duram por semanas ou meses podem acontecer em alguns casos. Essa afirmação pode explicar o fato de alguns animais no momento da coleta não apresentarem macro-hematúria.

A macro-hematúria pode ser confundida com hemoglobinúria, devendo ser estabelecido o diagnóstico diferencial, como citado por ToKARnia et al. (1979). Esse procedimento pode ser feito na própria fazenda, coletando-se a urina do animal e verificando a formação de sedimento, o que não ocorre quando se tem hemoglobinúria por hemoparasitoses ou qualquer outra causa (MARÇAL, 2000).

Em relação à quantidade de material obtido, observou-se que o volume final de liquido vesical nos animais do grupo $\mathrm{A}$ variou de $300 \mathrm{~mL}$ a 2 litros, enquanto que nos do grupo B, variou de 15 a $60 \mathrm{~mL}$. A qualidade dos esfregaços foi dependente da existência de macro ou micro-hematúria nos animais avaliados. Observou-se que nas amostras com maior quantidade de sangue a confecção dos esfregaços e posterior avaliação citológica foram dificultadas.

RASKin; MeYer (2011) afirmaram que uma aplicação da citologia é classificar as lesóes para auxiliar o diagnóstico, o prognóstico e a conduta de um caso. Entretanto, existem
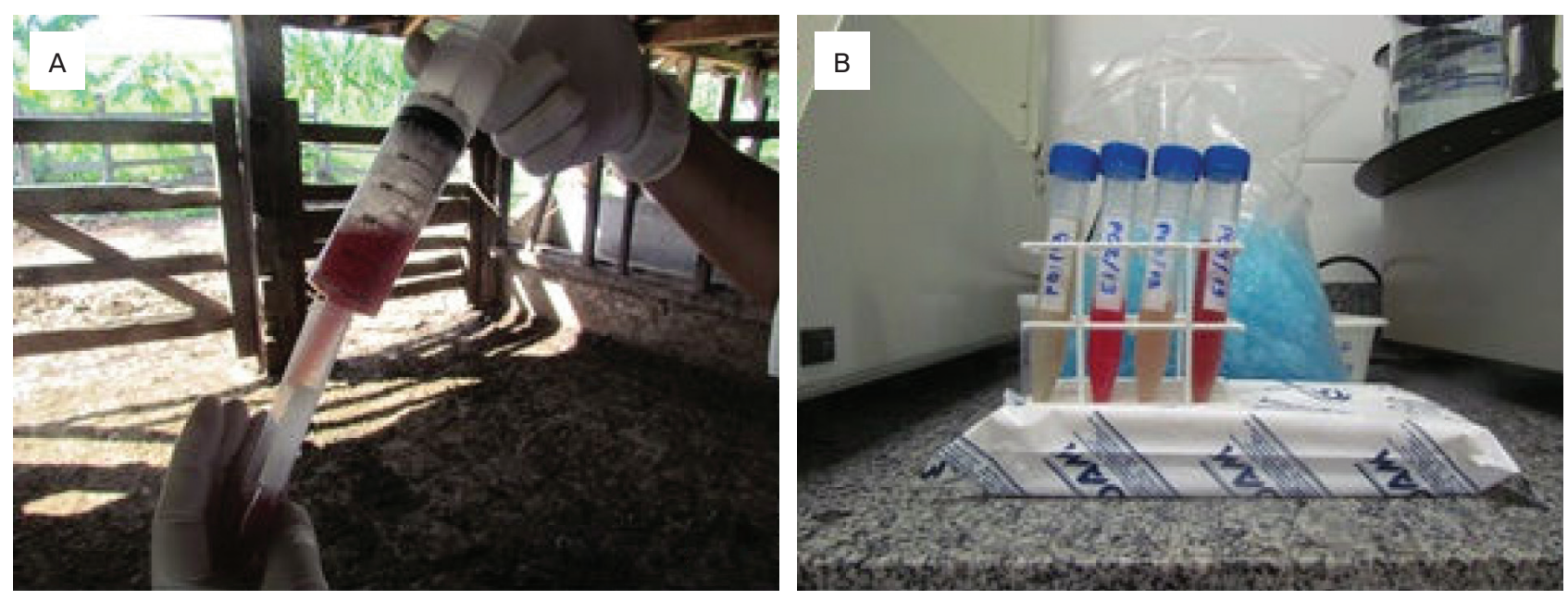

Figura 3. Recuperação do lavado vesical do grupo B. (A) Recuperação do último volume aspirado do lavado; (B) amostras armazenadas em tubos plásticos tipo Falcon com capacidade de $15 \mathrm{~mL}$, devidamente identificados. 
amostras que geram interpretaçóes não diagnósticas. Essas geralmente resultam de material com celularidade insuficiente, ou com excessiva contaminação sanguínea. Neste estudo, as amostras com menor celularidade foram obtidas exatamente dos animais com quadros de hematúria mais graves, tendo sido difícil minimizar os artefatos ocorridos devido a essa contaminação sanguínea durante a fase de confecção dos esfregaços citológicos, no entanto, foi possível avaliar todo o material obtido. Por outro lado, Collaço et al. (2005) citaram que a qualidade do material em citopatologia baseia-se em um conjunto de medidas destinadas a detectar, corrigir e reduzir deficiências do processo de produção dentro do laboratório, proporcionando o aperfeiçoamento dos procedimentos laboratoriais e minimizando a ocorrência de erros diagnósticos, servindo também como orientação para a melhoria da coleta do material e ferramenta educacional.

De acordo com Pajtler et al. (2006) e Pittoli et al. (2003), em experimentos com esfregaços cervicais de humanos, existem ainda outros fatores relacionados à qualidade do esfregaço citopatológico, tais como a presença de células anormais, escassas e pequenas, que contribuem para a ocorrência de resultados falso-negativos e também para a avaliação citopatológica no geral.

No que diz respeito à média do número de células por amostra, observou-se que no grupo A foi de 1,8 a 52; enquanto no grupo B foi de 5,8 a 25,8. A média do número de células obtidas por grupo foi de 19,8 \pm 20,0 e 16,8 \pm 9,2 nos grupos $\mathrm{A}$ e $\mathrm{B}$, respectivamente, não revelando diferença significativa ( $\mathrm{p}>0,05)$. Os dados referentes à contagem de células estão dispostos na Tabela 1 .

No grupo A, em que foi recuperado todo o líquido vesical, esperava-se obter maior celularidade devido ao maior volume aspirado. Entretanto, em duas amostras, o número médio de células foi baixo, 1,8 e 7. É importante destacar que os animais dos quais essas amostras foram obtidas apresentavam quadros clínicos distintos, um apresentava micro-hematúria e histórico de ausência de sangue na urina há mais de seis meses e o outro, embora apresentasse macro-hematúria no momento da coleta, tinha histórico de remissão da hematúria por mais de dois meses. É possível que esses quadros clínicos tenham influenciado na ocorrência de lesóes uroteliais discretas e, por isso, houve pouca descamação celular.

No grupo $\mathrm{B}$, o número médio de células foi aproximado ao do grupo A, embora tenha revelado menor desvio padrão. Nesse grupo todos os animais avaliados apresentavam macro-hematúria e, provavelmente, em seu epitélio vesical existiam lesôes que provocaram uma maior esfoliação celular.

O fato de não haver diferença significativa entre os grupos em relação à média do número de células obtidas sugere que os dois métodos de coleta utilizados poderiam ser empregados na obtenção de amostras para diagnóstico de HEB.

A quantidade de células inflamatórias e células epiteliais obtidas por amostra revelou que, nos dois grupos, todos os animais apresentavam mais células inflamatórias do que epiteliais, entretanto, a análise estatística revelou que o tipo celular encontrado independe do tipo de colheita realizado, náo havendo diferença significativa ( $>$ > 0,05) (Tabela 2).

$\mathrm{O}$ fato de não haver diferença significativa entre os grupos em relação ao número de células ou aos tipos celulares encontrados permite sugerir que a técnica mais viável para ser utilizada em bovinos seria a de recuperação do último lavado. Acredita-se que por se tratar de animais de produção, a recuperaçáo de todo o lavado poderia gerar um volume excessivo de líquido que dificultaria o acondicionamento e transporte até o laboratório, além de necessitar maior quantidade de centrifugações até a obtenção do volume final para confecção dos esfregaços.

$\mathrm{O}$ número total de células epiteliais observadas variou de 0 a 32 no grupo A e de 0 a 50 no grupo $\mathrm{B}$. O número de células inflamatórias variou de 5 a 248 e de 27 a 109, nos grupos A e B respectivamente. Esses dados estáo dispostos na Tabela 2.

Os dados revelaram que $70 \%$ das amostras apresentavam processo inflamatório (Fig. 4) conforme a classificação de Raskin; Meyer (2011). Segundo esses autores, quando a quantidade de células inflamatórias é igual ou ultrapassa $85 \%$ da contagem total é classificado como processo inflamatório.

Tabela 1. Valores absolutos do número total de células epiteliais e inflamatórias observadas em cada campo linear avaliado e valor médio de células encontrado em cada amostra de lavado vesical de bovinos positivos para hematúria enzoótica bovina.

\begin{tabular}{|c|c|c|c|c|c|c|c|}
\hline Grupo experimental & No da amostra & 1 * & $2 *$ & $3 *$ & $4^{*}$ & $5 *$ & Média \\
\hline \multirow{5}{*}{ Grupo A } & 25 & 26 & 19 & 23 & 20 & 32 & 24 \\
\hline & 26 & 10 & 17 & 24 & 13 & 8 & 14,4 \\
\hline & 27 & 3 & 1 & 2 & 1 & 2 & 1,8 \\
\hline & 28 & 7 & 12 & 4 & 8 & 4 & 7 \\
\hline & 29 & 57 & 79 & 41 & 47 & 35 & 52 \\
\hline \multirow{5}{*}{ Grupo B } & 3 & 22 & 17 & 29 & 14 & 16 & 19,6 \\
\hline & 5 & 15 & 29 & 21 & 28 & 36 & 25,8 \\
\hline & 10 & 7 & 6 & 10 & 15 & 5 & 8,6 \\
\hline & 11 & 49 & 13 & 18 & 29 & 11 & 24 \\
\hline & 12 & 9 & 4 & 3 & 6 & 7 & 5,8 \\
\hline
\end{tabular}

*Número total de células epiteliais e inflamatórias observadas por campo linear, objetiva de 40x. 
Em 4 casos (40\%) observou-se que 100\% das células encontradas eram inflamatórias.

Notou-se nos animais deste estudo maior prevalência de lesôes não neoplásicas, predominantemente inflamatórias. As alteraçôes histopatológicas observadas nas bexigas de animais com HEB podem ser divididas em neoplásicas e não neoplásicas; nessa última, incluem-se lesões inflamatórias, hiperplásicas e metaplásicas. É comum a ocorrência simultânea de algumas dessas lesóes na mesma bexiga (Реiхото et al., 2003).

Dados semelhantes a estes foram citados por Confer; Panciera (2001), que afirmaram que a lesão inicial observada na hematúria enzoótica é a cistite hemorrágica, resultando em hematúria persistente. De acordo com DurÃo et al. (1995), essa lesão parece surgir como resultado de hemorragias do córion sem soluçôes de continuidade na mucosa. A mucosa passa a ser hemorrágica, havendo sensível ectasia e congestão capilar (Confer; PANCiera, 2001).
Estes dados corroboram os achados de Carvalho et al. (2006), que verificaram que os animais acometidos podem apresentar cistite polipóide, cistite folicular, cistite cística e cistite glandular.

Um experimento realizado por Silva et al. (2012) na mesma região em que o presente estudo foi desenvolvido revelou cistite cística em 17,39\% dos animais. Entretanto, vale ressaltar que essas lesôes foram avaliadas por histopatologia, assim como as citadas anteriormente. Neste experimento, a avaliação das lesóes foi feita pela citopatologia, método que não permite a classificação dos tipos de cistite devido ao aspecto disperso das células epiteliais. Neste exame podem ser identificadas células inflamatórias, no entanto, o arranjo e a disposição das células epiteliais para determinação do tipo de cistite não é possível. De acordo com a classificação utilizada (RAskin; MEYer, 2011), os diagnósticos citopatológicos podem ser divididos em cinco categorias: tecido normal ou hiperplásico, massa cística, inflamação ou infiltração celular, reação à lesão do tecido

Tabela 2. Valores absolutos e percentuais do número de células epiteliais e inflamatórias observadas em cada amostra de lavado vesical de bovinos positivos para hematúria enzoótica bovina.

\begin{tabular}{|c|c|c|c|c|c|}
\hline $\begin{array}{l}\text { Grupo } \\
\text { experimental }\end{array}$ & $N^{\circ}$ da amostra & $\begin{array}{l}\text { Total de células } \\
\text { epiteliais }\end{array}$ & $\begin{array}{l}\text { Percentual de } \\
\text { células epiteliais }\end{array}$ & $\begin{array}{l}\text { Total de células } \\
\text { inflamatórias }\end{array}$ & $\begin{array}{l}\text { Percentual de células } \\
\text { inflamatórias }\end{array}$ \\
\hline \multirow{5}{*}{ Grupo A } & 25 & 32 & 26,6 & 88 & 73,4 \\
\hline & 26 & - & - & 72 & 100 \\
\hline & 27 & 4 & 44,5 & 5 & 55,5 \\
\hline & 28 & - & - & 35 & 100 \\
\hline & 29 & 12 & 4,6 & 248 & 95,4 \\
\hline \multirow{5}{*}{ Grupo B } & 3 & - & - & 98 & 100 \\
\hline & 5 & 20 & 15,5 & 109 & 84,5 \\
\hline & 10 & - & - & 43 & 100 \\
\hline & 11 & 50 & 41,6 & 70 & 58,4 \\
\hline & 12 & 2 & 6,8 & 27 & 93,2 \\
\hline
\end{tabular}
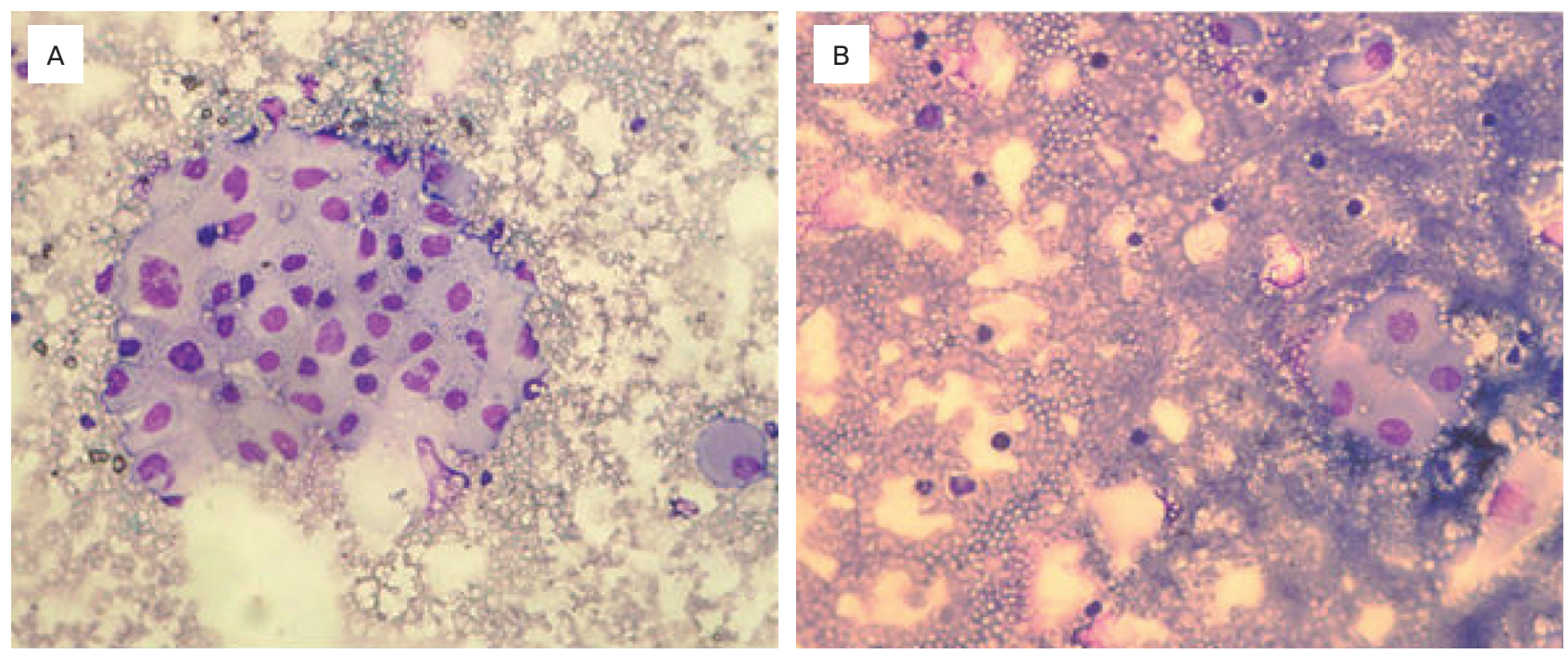

Figura 4. Fotomicrografia do lavado vesical de bovinos. (A) Predominância de células uroteliais; (B) células inflamatórias e células uroteliais. Coloração de Giemsa. Objetiva 40x. 
e neoplasia. Esses mesmos autores citaram que as condiçôes inflamatórias podem ser definidas não só pelo tipo celular envolvido, mas também pela sua predominância.

Desta forma, verifica-se que o uso do lavado vesical, por ser um método in vivo, poderia ser uma ferramenta importante para o diagnóstico precoce da HEB, uma vez que a maioria dos trabalhos sobre lesóes em bexiga de animais com HEB utiliza a histopatologia, que geralmente é feita em animais mortos provenientes de abate ou mesmo de exames post-mortem.

Embora as alteraçóes inflamatórias tenham sido mais frequentes neste estudo, Mcgavin; ZaChary (2009) citaram que condiçôes ou processos inflamatórios crônicos aumentam o risco de câncer nos órgãos afetados. Acredita-se que as lesōes não neoplásicas funcionam como lesóes pré-neoplásicas, causando, dessa forma, a progressão tumoral. Esses dados foram confirmados por FrANCO et al. (2010), que afirmaram que lesóes como displasia, metaplasia e inflamação são lesōes pré-neoplásicas que podem evoluir para neoplasias, caso não seja retirado o agente agressor.

As células epiteliais foram encontradas em $60 \%$ dos casos e as alteraçôes morfológicas observadas foram muito discretas, não sendo possível classificar nenhuma amostra como hiperplásica ou neoplásica. Observou-se relação núcleo/citoplasma aumentada em $20 \%$ dos casos, mitoses atípicas em $10 \%$ e nenhuma amostra revelou nucléolo evidente.

Os principais critérios de malignidade aplicáveis na avaliação da citologia de um esfregaço, segundo análise de AlLEN et al. (1986) são: grande densidade celular no esfregaço, células com baixo grau de coesão e presença de células "nuas" em abundância, variabilidade nas dimensōes dos núcleos (anisocariose); padrōes irregulares de distribuiçáo de cromatina (granular ou reticular) nuclear, figuras de mitose normais e anormais, presença de vários nucléolos no mesmo núcleo ou macronucléolos. Com base nos critérios citados por esses autores é necessário que se encontre diversas alteraçôes simultaneamente para que uma amostra seja classificada como neoplásica.

Esses dados foram confirmados por ZuCCARI et al. (2001), que afirmaram que o padrão nuclear se mostra decisivo no diagnóstico de neoplasias, visto que a presença de um ou mais nucléolos e o padráo irregular da cromatina só podem estar presentes em tecidos neoplásicos. No mesmo estudo realizado em neoplasias mamárias de cadelas, os critérios mais específicos como figuras de mitose anormais, molde e dobra nuclear, distorçôes citoplasmáticas, entre outras, se mostraram de menor importância no diagnóstico de malignidade tumoral, uma vez que o importante, na citologia, é o conjunto de modificaçôes no grupo celular como um todo.

Neste estudo acredita-se que a ausência de processos neoplásicos observados nos animais com HEB por meio da citopatologia, pode estar relacionada à baixa celularidade obtida nas amostras. Desta maneira, o emprego de técnicas moleculares utilizando biomarcadores seria importante para detectar precocemente lesôes pré-neoplásicas ou neoplásicas nestes animais.

\section{CONCLUSÕES}

Os dados deste estudo permitiram concluir que o exame citopatológico do lavado vesical de bovinos pode auxiliar no diagnóstico da HEB e que os dois métodos de colheita empregados mostraram-se adequados para obtenção de amostras viáveis.

A avaliação citopatológica permitiu a identificação de lesôes não neoplásicas predominantemente inflamatórias. Acredita-se que a utilização de técnicas moleculares com biomarcadores em amostras citológicas seria importante para detectar precocemente lesóes pré-neoplásicas ou neoplásicas nesses animais.

\section{AGRADECIMENTOS}

À Fundação de Amparo à Pesquisa do Estado do Espírito Santo pelo suporte financeiro (Processo no 45440409/2009).

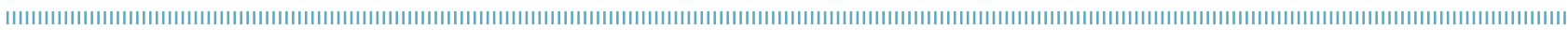
REFERÊNCIAS

ALLEN, S.W.; PRASSE, K.W.; MAHAFFEY, E.A. Cytologic differentiation of benign from malignant canine mammary tumors. Veterinary Pathology, v.23, n.6, p.649-655, 1986.

BENESI, F.J.; WACHHOLZ, L.; BERTAGNON, H.G.; LEAL, M.L.R.; MORI, E.; FERNANDES, W.R. Citologia dos lavados traqueobrônquico (LTB) e broncoalveolar (LBA) de bezerros holandeses sadios durante o primeiro mês de vida. Pesquisa Veterinária Brasileira, v.32, n.3, p.267-270, 2012.
CARNEIRO, L.C. Endometrite citológica em vacas leiteiras mestiças e vacas de corte nelore: incidência e relação com o desempenho reprodutivo. 201 1. 79f. Dissertação (Mestrado em Ciências Veterinárias) - Faculdade de Medicina Veterinária, Universidade Federal de Uberlândia, Uberlândia, 2011.

CARVALHO, T.; PINTO, C.; PELETEIRO, M.C. Urinary bladder lesions in bovine enzootic hematuria. Journal of Comparative Pathology, v.134, n.4, p.336-346, 2006. 
COLLAÇO, L.M.; NORONHA, L.; BLEGGI-TORRES, L.F.; PINHEIRO, D.L. Quality control in cervical cancer screening: Brazilian experience. Acta Cytologica, v.49, n.6, p.694-696, 2005.

CONFER, A.W.; PANCIERA, R.J. The urinary system. In: CARLTON, W.W.; ZACHARY, J.F. Thomson's Special Veterinary Pathology. 3 ed. St Louis: Mosby; 2001. p.235-277.

DURÃO, J.F.C.; FERREIRA, M.L.; CABRAL, A. Aspectos anatomopatológicos e clínicos da hematúria enzoótica dos bovinos. Revista Portuguesa de Ciências Veterinárias, v.5, n.1, p. 11-20, 1995.

FRANCO, M.; MONTENEGRO, M.R.; BRITO, T.; BACCHI, C.E.; ALMEIDA, P.C. Patologia: processos gerais. 5 ed. Atheneu: São Paulo; 2010. 329p.

GOMES, V.; MADUREIRA, K.M.; DELLA LIBERA, A.M.M.P.; BLAGITZ, M.G.; ALVES, M.; BAPTISTELLA, F.; BENESI, F.J. Dinâmica da celularidade do colostro de vacas da raça Holandesa no pós-parto imediato. Arquivo Brasileiro de Medicina Veterinária e Zootecnia, v.63, n.5, p.1047-1053, 2011.

MARÇAL, W.S. A toxidez da samambaia nos bovinos. Saúde animal; 2000. Disponível em: <http://www.saudeanimal.com.br/bovino_ samambaia.htm>. Acesso em: 10 nov. 2011.

MAXIE, M.G.; NEWMAN, S.J. Urinary system. In: MAXIE, M.G. (Ed.) Jubb, Kennedy, and Palmer's Pathology of Domestic Animals. 5 ed. Philadelphia: Saunders Elsevier; 2007. cap. 4, p.425-522.

MCGAVIN, M.D.; ZACHARY, J.F. Bases da Patologia em Veterinária. 4 ed. Elsevier: Rio de Janeiro; 2009. 1476p.

NUNES, L.C. Aspectos clínico-epidemiológicos da hematúria enzoótica bovina na região sul do Espírito Santo. Vitória: Jornal de Olho no Amanhã; 2009. p.4-5.

PAJTLER, M.; AUDY-JURKOVIĆ, S.; SKOPLJANAC-MACINA, L.; ANTULOV, J.; BARISIĆ, A.; MILICIĆ-JUHAS, V. Rapid cervicovaginal smear screening: method of quality control, and assessing individual cytotechnologist performance. Cytopathology, v.17, n.3, p.121-126, 2006.

PAMUKCU, A.M.; PRICE, J.M.; BRYAN, G.T. Naturally occurring and Bracken-Fern Induced bovine urinary bladder tumors-clinical and morphological characteristics. Veterinary Pathology, v.13, n.2, p. $110-122,1976$.
PEIXOTO, P.V.; FRANÇA, T.N.; BARROS, C.S.L.; TOKARNIA, C.H. Histopathological aspects of bovine enzootic hematuria in Brazil. Pesquisa Veterinária Brasileira, v.23, n.2, p.65-81, 2003.

PITTOLI, J.E.; MELLO, E.S.; PEREIRA, S.M.M.; MAEDA, M.Y.S.; UTAGAWA, M.L.; CELESTINO, J.D.; LORETO, C. Revisão de esfregaços cervicais negativos em pacientes com lesões intraepiteliais de alto grau. Jornal Brasileiro de Patologia e Medicina Laboratorial, v.39, n.3, p.219-221, 2003.

RASKIN, E.R.; MEYER, D.J. Atlas de citologia de cães e gatos. 2 ed. São Paulo: Elsevier; $2011.472 p$.

ROSENBERGER, G. Nature, manifestations, cause and control of chronic enzootic haematuria in cattle. Veterinary Medical Review, v.2, p.189-206, 1971.

SILVA, M.A. SCÁRDUA, C.M.; DÓREA, M.D.; NUNES, L.C.; MARTINS, I.V.F.; DONATELE, D.M. Prevalência de hematúria enzoótica bovina em rebanhos leiteiros na microrregião do Caparaó, Sul do Espírito Santo, entre 2007 e 2008. Ciência Rural, v.39, n.6, p.1847-1850, 2009.

SILVA, M.A.; SOUSA, D.R.; MADUREIRA, A.P.; NUNES, L.C. Caracterização histopatológica de bexigas associadas à hematúria enzoótica bovina. Revista Brasileira de Medicina Veterinária, v. 34, n. 4, p. 319-326, 2012

SOCIEDADEBRASILEIRA DE UROLOGIA E SOCIEDADE BRASILEIRA DE PATOLOGIA. Câncer de bexiga: diagnóstico. Revista da Associação Brasileira de Medicina, v.54, n.2, p.100-101, 2008. Disponível em: <http://www.scielo.br/scielo.php?script=sci_ arttext\&pid=SO 104-42302008000200006\&lng=en\&nrm =iso>. Acesso em: 04 dez. 2012.

TOKARNIA, C.H.; DÖBEREINER J.; PEIXOTO P.V. Plantas tóxicas do Brasil. Rio de Janeiro: Helianthus; 2000. 310p.

TOKARNIA, C.H.; DÖBEREINER, J.; SILVA, M.F. Plantas tóxicas da Amazônia a bovinos e outros herbívoros. Manaus: Instituto Nacional de Pesquisas da Amazônia; 1979. 95p.

VENTURA, R.F.A.; COLODEL, M.M.; ROCHA, N.S. Exame citológico em medicina veterinária: estudo retrospectivo de 11.468 casos (19942008). Pesquisa Veterinária Brasileira, v.32, n.1 1, p.1 169-1 173, 2012.

ZUCCARI, D.A.P.C.; SANTANA, A.E.; ROCHA, N.S. Correlação entre a citologia aspirativa por agulha fina e a histologia no diagnóstico de tumores mamários de cadelas. Brazilian Journal of Veterinary Research and Animal Science, v.38, n. 1, p.38-41, 2001. 